\title{
Comparative Assessment of Critical Quality Attributes of Sildenafil Tablets
}

\author{
Marta I.V. Brevedan ${ }^{1}$, María A. Varillas ${ }^{1}$, and Noelia L. Gonzalez Vidal ${ }^{1,2 *}$ \\ ${ }^{1}$ Departamento de Biología, Bioquímica y Farmacia, Universidad Nacional del Sur, Bahía Blanca, Argentina. \\ ${ }^{2}$ Consejo Nacional de Investigaciones Científicas y Técnicas, Bahía Blanca, Argentina.
}

e-mail: nlgvidal@uns.edu.ar

\section{ABSTRACT}

Sildenafil citrate is a selective inhibitor of the enzyme phosphodiesterase type 5 , used to treat erectile dysfunction in adults and pulmonary hypertension, mainly in children. This work aimed to perform a comparative study of sildenafil tablets marketed in Argentina and establish their pharmaceutical equivalence. Eight commercial formulations (immediate-release tablets) containing $50 \mathrm{mg}$ of sildenafil were analyzed according to United States and Argentinian Pharmacopoeial guidelines. The assay was performed by UV spectrophotometry in $0.01 \mathrm{~N}$ hydrochloric acid. Similar conditions were used for dissolution tests, which were carried out in a basket apparatus at $100 \mathrm{rpm}$. All samples met pharmacopeial specifications for acceptance (i.e., assay, content uniformity, hardness, friability, disintegration, and in vitro dissolution) for immediate-release dosage forms. When compared to the reference formulation, a statistically significant difference was noted for dissolution efficiency in one case (sample F). Based on the obtained results, it is possible to conclude that the evaluated formulations of sildenafil can be considered pharmaceutical equivalents.

KEYWORDS: Dissolution profiles, pharmaceutical equivalence, sildenafil tablets

\section{INTRODUCTION}

\begin{abstract}
ildenafil citrate is a selective inhibitor of the phosphodiesterase (PDE) type 5 enzyme, widely used for erectile dysfunction treatment in adults $(1,2)$. The drug was first approved by the U.S. Food and Drug Administration (FDA) in March 1998 after 2 years of being patented; the drug was initially proposed to treat hypertension and angina pectoris (3). Later in 2005, the FDA approved the application of sildenafil citrate to treat pulmonary hypertension in adults and pediatric patients $(2,4)$. Different provisional biopharmaceutical classifications for sildenafil citrate have been described in the literature, and Miranda et al. confirmed that sildenafil citrate can be classified as a class II drug in the Biopharmaceutical Classification System (BCS) based on solubility and permeability data (1). According to the criteria of World Health Organization (WHO), FDA, and European Medicines Agency (EMA), the BCS-based biowaiver procedure cannot be recommended for immediate-release formulations of sildenafil citrate, and its interchangeability would not be fully guaranteed through in vitro similarity studies (1).
\end{abstract}

The WHO indicates that products can be considered pharmaceutical equivalents if they contain the same amount of active substance, use the same route of administration, and meet identical or comparable quality standards (5). The Argentinian pharmaceutical market is not depicted by generic drugs in a strict sense; rather, sildenafil immediate-release solid oral dosage forms are offered as one reference product and several multisource products. Patients frequently replace 
the reference product with a multisource formulation for economic reasons, regardless of quality. In 1998, sildenafil citrate was only commercialized by the pharmaceutical laboratory that patented it, Pfizer. Today, it is offered by more than 30 laboratories in Argentina. Despite it being a prescription medicine, evidence indicates that sildenafil is sold without a prescription. According to the Argentine Pharmaceutical Confederation (COFA), in 2013 almost 3.6 million sildenafil tablets were sold in pharmacies in Argentina, and another 3 million units were sold on the Internet and illegal sites (e.g., convenience stores, hotels, motels) (6).

Since consumers of sildenafil tablets in Argentina interchange formulations without any control, it became crucial to compare commercial products, at least in technical terms. To the extent of our knowledge, very few studies have been published in the literature concerning pharmaceutical equivalence of sildenafil citrate products, and none regarding samples from the Argentine market. A study in Costa Rica compared the innovator with a generic product in terms of dosage form uniformity (7). Similarly, a study performed in Nigeria compared nine products, but only in terms of sildenafil citrate content (8). Another study performed by Deconinck et al. in Belgium evaluated the reference product and 17 counterfeit products containing sildenafil citrate, including tablets, capsules, and an oral gel (9). Thus, the purpose of the present work was to assess and compare the critical quality attributes, including in vitro dissolution, for the pharmaceutical characterization of sildenafil tablets from the Argentine market and evaluate their pharmaceutical equivalence.

\section{MATERIALS AND METHODS}

\section{Chemicals and Reagents}

Sildenafil citrate was purchased from Saporiti (Parafarm, Argentina). Analytical grade hydrochloric acid $(\mathrm{HCl}$ ) (Anedra, Argentina) was used to evaluate sildenafil concentration in different tests (i.e., assay, content uniformity, and in vitro dissolution).

\section{Sildenafil Products}

Eight commercial formulations, i.e., immediate-release coated tablets containing $50 \mathrm{mg}$ of sildenafil, randomly labeled from $\mathrm{A}$ to $\mathrm{H}$, were included in this study. All multisource products corresponded to national industries, whereas the reference formulation $(E)$ was imported from Mexico. The samples were obtained from local pharmacies in Bahia Blanca city (Buenos Aires province) and were analyzed within their shelf life.

\section{Equipment}

Sildenafil concentration was assessed during the assay and in vitro dissolution testing using a UV spectrophotometer (Varian Cary 50 Conc, Varian Instruments, Australia). Three testers, i.e., DGM02, FGMO2, and EGMO2 (Scout Electronics, Argentina), were used to measure hardness, friability, and disintegration, respectively. A dissolution tester (DT60, Erweka GmbH, Germany) was used for in vitro dissolution assessment. Materials and tablets were weighed using an electronic analytical balance (Acculab ALC-210.4M, USA).

\section{Methods for Evaluation of Critical Quality Attributes}

A comparative study of the information included in patient leaflets and labels of primary and 
secondary packaging was included in the analysis to evaluate the extent of agreement with national legislation $(10,11)$.

Ten tablets from each product were randomly selected for evaluation of weight variation. The results were expressed as mean weight \pm standard deviation (SD).

Argentine Pharmacopeia guidelines were followed for friability, hardness, and disintegration tests (10). First, 10 tablets from each product were weighed before and after the friability procedure (100 revolutions of the friability tester); results (weight loss) were expressed as percentage. The maximum acceptable result is a value not higher than $1 \%(10)$. Second, another 10 tablets from each product were evaluated using the hardness tester; results were expressed as the degree of force (in $\mathrm{kp}$ ) required to break the tablet. Disintegration tests were performed in distilled water at $37.0 \pm 2.0^{\circ} \mathrm{C}$ using six tablets of each product. The results were expressed as the maximum time needed for complete disintegration of each tablet, which should be lower than 30 minutes (10).

For sildenafil content evaluation, an accurately weighed amount of powder, obtained from 10 weighed and ground tablets of each product, was dissolved using $0.01 \mathrm{~N} \mathrm{HCl}$. The filtered solution (0.45- $\mu \mathrm{m}$ pore-size nylon membrane filter, Gamafil, Argentina) was diluted with the same reagent, and the sildenafil concentration was assessed by spectrophotometric analysis at $292 \mathrm{~nm}$ (12). The UV methodology was previously compared with the official method, with no significant differences detected between results $(p>0.05)(13)$. Therefore, a sildenafil standard calibration curve ( $\mathrm{y}=0.0299 \mathrm{x}-0.0056 ; R^{2}=1$ ) was developed for content determination and used for the assay and uniformity tests (i.e., 10 tablets of each product were individually assayed).

Dissolution tests were performed according to United States Pharmacopeia (USP) (13). The applied conditions involved testing in an apparatus 1 (basket) at an agitation speed of $100 \mathrm{rpm}$, with an exact volume $(900 \mathrm{~mL})$ of dissolution medium $(0.01 \mathrm{~N} \mathrm{HCl})$ at $37.0 \pm 0.5 \stackrel{\circ}{ } \mathrm{C}$. At pre-selected time intervals $(5,10,15$, and $20 \mathrm{~min})$, aliquots were withdrawn, suitably filtered $(0.45-\mu \mathrm{m}$ poresize nylon membrane filter, Gamafil), diluted, and assayed by UV spectrophotometry (292 nm). A standard calibration curve was concomitantly constructed $\left(y=0.0298 \mathrm{x}-0.0003 ; R^{2}=0.9999\right.$; concentration range $=4.0-34.0 \mu \mathrm{g} / \mathrm{mL}$ ) for the determination of dissolved sildenafil. The USP specification for dissolution tests states that not less than $80 \%$ (Q) of the labeled amount of sildenafil should dissolve within 15 min (13). In addition, a statistical comparison of dissolution efficiency (DE) was performed via analysis of variance (ANOVA). DE is defined as the ratio, in percentage, of the area under the curve obtained from the dissolution profile, with the total area of the rectangle considered as $100 \%$ dissolution for the same time interval (14).

\section{RESULTS AND DISCUSSION}

The comprehensive concept of pharmaceutical equivalence includes not only the properties of the active pharmaceutical ingredient and pharmaceutical form but also the instructions for use and storage (especially when these instructions are crucial for stability and shelf-life of the product). For this reason, the information presented on labels (primary and secondary packaging) and patient leaflets of the evaluated products was compared according to WHO guidelines and national regulations $(5,10,11)$. The official monograph states for sildenafil tablets says to "Preserve in well-closed containers. Store at controlled room temperature" (13). The conditions 
for packaging and storage declared by manufacturers of the evaluated formulations are presented in Table 1, where several differences were recorded. Only the labels of formulations A and D specified to "store in its original packaging." The label information matched the recommendations described in the leaflet. Products $A, D, F, G$, and $H$ indicated a temperature range for storage, but products $B, C$, and $E$ only referred to a maximum temperature. Moreover, it is essential that information declared in labels and leaflets is uniform between the different commercial products and ascertained by regulatory agencies to avoid misunderstandings among patients, care givers, and medical professionals.

Table 1. Information of Evaluated Products and Results of Physical Quality Control Tests of Sildenafil (50-mg) Tablets

\begin{tabular}{|c|c|c|c|c|c|}
\hline Product & Price $^{a}$ & Storage Conditions ${ }^{b}$ & Weight $(\mathrm{mg})^{c}$ & $\begin{array}{l}\text { Hardness } \\
\text { (kp) }^{c}\end{array}$ & $\begin{array}{l}\text { Disintegration } \\
\text { time }(s)^{d}\end{array}$ \\
\hline A & 41.95 & $\begin{array}{l}\text { Store at a room temperature } \\
\text { between } 15 \text { and } 30{ }^{\circ} \mathrm{C} \text {, protected } \\
\text { from light in original container }\end{array}$ & $410.7 \pm 3.7$ & $14.9 \pm 0.4$ & 85 \\
\hline B & 57.50 & $\begin{array}{l}\text { Store at room temperature not } \\
\text { higher than } 30^{\circ} \mathrm{C}\end{array}$ & $365.1 \pm 4.8$ & $9.4 \pm 0.8$ & 26 \\
\hline C & 50.00 & $\begin{array}{l}\text { Do not expose to temperatures } \\
\text { above } 30^{\circ} \mathrm{C}\end{array}$ & $308.4 \pm 1.4$ & $13.0 \pm 4.1$ & 29 \\
\hline D & 44.00 & $\begin{array}{l}\text { Store in original container } \\
\text { between } 15 \text { and } 30{ }^{\circ} \mathrm{C} \text { and dry } \\
\text { place and protected from light }\end{array}$ & $315.1 \pm 1.7$ & $9.4 \pm 0.2$ & 97 \\
\hline E (Ref) & 73.70 & $\begin{array}{l}\text { Store at a temperature below } \\
30^{\circ} \mathrm{C}\end{array}$ & $311.1 \pm 4.2$ & $14.0 \pm 3.6$ & 159 \\
\hline $\mathbf{F}$ & 52.50 & $\begin{array}{l}\text { Store at room temperature, } \\
\text { preferably between } 15 \text { and } 30^{\circ} \mathrm{C}\end{array}$ & $302.4 \pm 4.1$ & $19.2 \pm 0.9$ & 436 \\
\hline G & 77.29 & Store between 15 and $30^{\circ} \mathrm{C}$ & $418.7 \pm 4.2$ & $13.3 \pm 0.7$ & 114 \\
\hline H & 56.00 & $\begin{array}{l}\text { Store at room temperature, } \\
\text { between } 15 \text { and } 30^{\circ} \mathrm{C}\end{array}$ & $305.5 \pm 4.4$ & $11.0 \pm 0.2$ & 47 \\
\hline
\end{tabular}

${ }^{a}$ Price per tablet in Argentine pesos at the time of analysis.

${ }^{b}$ Information presented in labels and leaflets.

${ }^{c}$ Mean $\pm S D$

${ }^{d}$ Maximum time needed for complete disintegration of evaluated tablets.

Ref: reference formulation.

As mentioned earlier, in Argentina, economic reasons represent the major factor concerning the extensive use of multisource products and the interchangeability decisions taken by patients. Sildenafil products revealed a wide range of selling prices in this particular market; notably, products $E$ (reference) and $G$ were almost $80 \%$ higher than products $A$ and D (Table 1 ).

The results for weight variation, friability, and disintegration tests are also shown in Table 1. Differences were recorded between the mean weights of each product, with results in ranging from 302.4 to $418.7 \mathrm{mg}$. These observations could be attributed to differences in qualitative and quantitative excipient composition according to each formula and manufacturing process, which 
consequently affects the size and shape of each product, with no strict relation to differences in drug content or dissolution performance. Mean hardness results ranged from 9.4 to $19.2 \mathrm{kp}$, which indicated suitable mechanical behavior because the results were all above the acceptable value, $2.0 \mathrm{kp}$. All formulations complied with the friability test because a very slight loss of powder was recorded ( $<0.5 \%$ in all cases, data not shown), with values below the maximum allowed (10). With respect to disintegration results, all formulations fulfilled the Argentine Pharmacopeia specifications, with values between 26 seconds and 17 minutes (10).

The assay results are shown in Table 2. Mean \pm SD values ranged from $93.5 \% \pm 4.3$ (B) to $100.1 \%$ \pm 2.6 ( $E$, reference). The reference formulation and products $A$ and $F$ met USP specifications for dissolution in Stage 1, and the remaining products met the specifications in Stage 2 (Table 2). All of the evaluated formulations can be classified as "very fast dissolving" (i.e., $\geq 85 \%$ within $15 \mathrm{~min}$ ). Therefore, all formulations fulfilled the official specifications for these critical quality attributes (i.e., assay, uniformity of dosage units, hardness, friability, disintegration, and in vitro dissolution) $(10,13)$.

Table 2. Assay, Uniformity, and Dissolution Results for Sildenafil (50 mg) Tablets

\begin{tabular}{|c|c|c|c|c|}
\hline Product & Assay $^{\mathbf{a}}$ & $\begin{array}{c}\text { Uniformity of Dosage } \\
\text { Units (Range / RSD) }\end{array}$ & $\begin{array}{c}\text { Dissolution Test at S1 } \\
\text { Stage (Range / RSD) }^{\mathbf{c}}\end{array}$ & $\begin{array}{c}\text { Dissolution } \\
\text { Efficiency }\end{array}$ \\
\hline A & $98.1 \pm 7.2$ & $93.3-113.2 / 7.6$ & $87-90 / 1.3$ & $78.6 \pm 1.0$ \\
\hline B & $93.5 \pm 4.3$ & $88.3-98.7 / 5.6$ & $84-90 / 2.6$ & $76.7 \pm 1.3$ \\
\hline C & $94.5 \pm 6.4$ & $85.0-99.4 / 6.0$ & $84-100 / 6.0$ & $80.7 \pm 5.3$ \\
\hline D & $98.3 \pm 0.6$ & $98.4-99.1 / 0.4$ & $84-87 / 1.4$ & $76.8 \pm 1.2$ \\
\hline E (Ref) & $100.1 \pm 2.6$ & $98.2-101.0 / 1.5$ & $86-93 / 2.9$ & $78.7 \pm 2.0$ \\
\hline F & $97.8 \pm 0.7$ & $98.0-98.8 / 0.4$ & $85-91 / 2.4$ & $73.1 \pm 3.8$ \\
\hline G & $97.9 \pm 1.4$ & $97.5-98.4 / 0.4$ & $82-92 / 3.5$ & $78.2 \pm 3.8$ \\
\hline H & $94.5 \pm 2.0$ & $95.2-96.2 / 0.5$ & $79-92 / 6.6$ & $75.7 \pm 4.6$ \\
\hline
\end{tabular}

Data are mean percent of labeled amount $\pm S D$ unless otherwise noted.

aspecification for acceptance: $90.0-110.0 \%$.

${ }^{b}$ Specification for acceptance: $85.0-115.0 \% ; R S D<6 \%$.

'USP specification for acceptance: $80 \%(Q)$ in $15 \mathrm{~min}$.

Ref: reference formulation; RSD: relative standard deviation; Q: amount of dissolved active pharmaceutical ingredient, specified in the individual monograph, expressed as a percentage of labeled content of the dosage unit.

The evaluation of in vitro dissolution is essential for the assessment of the formulation performance in terms of batch quality and similarity between commercial (multisource or reference) products. Dissolution profiles of sildenafil formulations were constructed based on the mean percentage $( \pm S D$ ) of labelled amount dissolved at each sampling time (Fig. 1). It can be seen in Figure 1 that samples $B, C, D$, and $E$ reached maximum dissolution at 5 minutes, whereas samples $A, G$, and $H$ reached the plateau at 10 minutes. At 5 minutes, all formulations showed 
dissolved percentages above $85 \%$ except for product $F$, which dissolved $73 \%$ at that time, then reached its maximum at $15 \mathrm{~min}$. This result was in accordance with the disintegration time of formulation F, which was the highest value obtained (Table 1). Furthermore, this product exhibited a higher hardness result compared to the other products (Table 1). Higher disintegration and hardness test results could be related to the lowest dissolution rate obtained for product $F$.

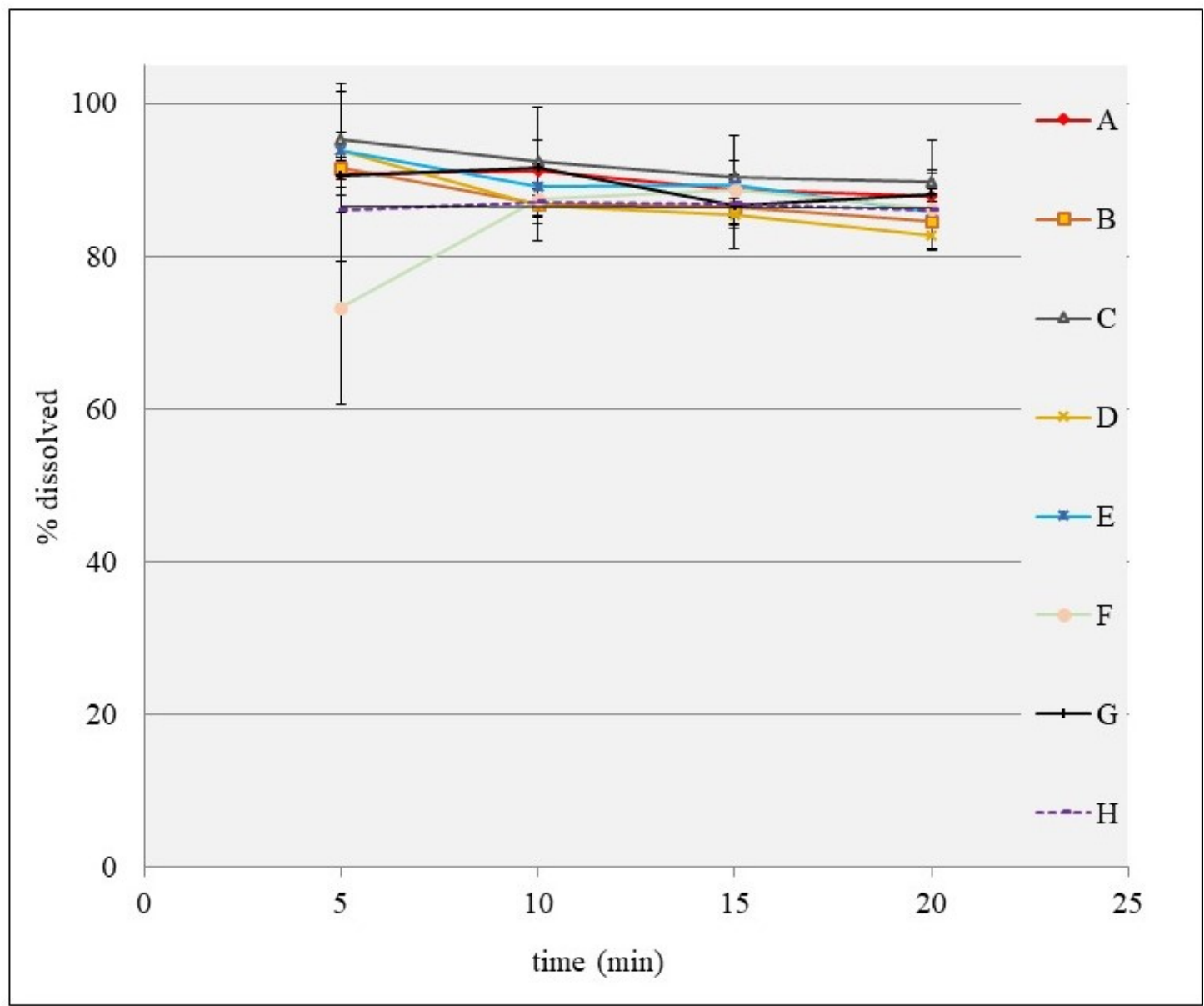

Figure 1. Dissolution profiles of sildenafil $(50 \mathrm{mg})$ immediate-release tablet formulations (mean percentage of labeled amount dissolved $\pm S D$ ); sample $E$ is reference formulation.

Dissolution profiles were compared base on the DE parameter. If a formulation presents high values of $D E$, it can be inferred that it would be rapidly available for permeation across physiologic membranes and, in consequence, it would not present bioavailability concerns. All DE results were higher than $75 \%$, with the exception of product $F$ (Table 2). Statistically significant differences in $D E$ were noted for product $F$ when compared to the reference product and between multisource products (i.e., product F vs. A, C, E, and G; product C vs. B, D, F, and H).

Dissolution results may be influenced by different factors, e.g., disintegration rate, excipient composition, and manufacturing method (15). As already mentioned, the lower dissolution results obtained for product $F$ could be related to its higher hardness and disintegration time values; however, no direct relationship was observed between excipient composition and dissolution performance (Table 3). The manufacturing method is not publicly available, so it was 
not possible to evaluate this factor.

Table 3. Qualitative Composition of Excipients in Sildenafil (50 mg) Tablets

\begin{tabular}{|c|c|c|c|c|c|c|c|c|c|}
\hline \multirow{2}{*}{\multicolumn{2}{|c|}{ Excipients }} & \multicolumn{8}{|c|}{ Products } \\
\hline & & \multirow{2}{*}{$\begin{array}{l}\text { A } \\
+\end{array}$} & \multirow{2}{*}{$\frac{B}{-}$} & \multirow{2}{*}{$\frac{C^{b}}{-}$} & \multirow{2}{*}{$\frac{D^{c}}{+}$} & \multirow{2}{*}{$\begin{array}{c}\text { E } \\
(\text { Ref })^{b} \\
-\end{array}$} & \multirow{2}{*}{$\frac{F^{b}}{+}$} & \multirow{2}{*}{$\begin{array}{l}\text { G } \\
+\end{array}$} & \multirow{2}{*}{$\frac{\mathrm{H}^{\mathrm{b}}}{-}$} \\
\hline Fillers and & Lactose & & & & & & & & \\
\hline & Microcrystalline cellulose ${ }^{a}$ & + & + & + & + & + & + & + & + \\
\hline & $\begin{array}{l}\text { Anhydrous dibasic calcium } \\
\text { phosphate }\end{array}$ & + & + & + & - & + & + & + & + \\
\hline & Talc $^{a}$ & + & - & + & - & - & - & - & + \\
\hline Disintegrants & Croscarmellose sodium & + & + & + & + & + & + & + & + \\
\hline Glidants & Colloidal silicon dioxide & - & - & + & + & - & - & - & - \\
\hline \multirow[t]{3}{*}{ Lubricants } & Magnesium stearate & + & + & + & + & + & + & + & + \\
\hline & Poloxamer $^{a}$ & - & - & - & + & - & - & - & - \\
\hline & Polyethylene glycol & + & + & + & - & - & + & - & + \\
\hline Binders & $\begin{array}{l}\text { Hydroxypropyl } \\
\text { methylcellulose }^{a}\end{array}$ & + & - & + & - & - & + & - & - \\
\hline \multirow{6}{*}{$\begin{array}{l}\text { Coating and } \\
\text { coloring } \\
\text { agents }\end{array}$} & Aluminum lacquer & + & + & + & + & - & + & + & + \\
\hline & Opadry & - & + & - & - & + & - & + & - \\
\hline & Polyvinyl alcohol ${ }^{a}$ & - & - & - & - & - & - & - & + \\
\hline & Titanium dioxide $^{a}$ & + & + & + & - & - & + & - & + \\
\hline & Coloring agents & + & + & + & + & - & + & + & + \\
\hline & Triacetin & - & - & - & - & - & + & - & - \\
\hline \multirow[t]{2}{*}{ Others } & Castor oil & + & - & - & - & - & - & - & - \\
\hline & Simethicone & - & - & - & + & - & + & + & + \\
\hline
\end{tabular}

${ }^{a}$ This excipient has multiple functions.

${ }^{b}$ Label and/or leaflet inform qualitative and quantitative composition of excipients.

${ }^{c}$ Excipient composition was informed only in the label (no leaflet)

Ref: reference formulation; symbols + and-indicate presence and absence, respectively.

\section{CONCLUSION}

Since sildenafil citrate is a BCS class II drug, a waiver of bioequivalence (biowaiver) is not applicable for immediate-release solid oral dosage forms. The Argentine pharmaceutical market is mainly comprised of multisource products. In the particular case of sildenafil formulations, patients can obtain them without prescription and interchange among different brand names with no control. In this scenario, the evaluation of pharmaceutical equivalence becomes an important initial step in the assessment of critical quality attributes of multisource products. Based on the obtained results, it is possible to conclude that the evaluated $50-\mathrm{mg}$ sildenafil immediate-release tablets (reference and multisource products in the Argentine market) can be considered pharmaceutical equivalents. Furthermore, health advice is mandatory during dispensing of these medicinal products. 


\section{FUNDING}

The authors thank Universidad Nacional del Sur for financial support of this study (PGI24/ZB70).

\section{CONFLICT OF INTEREST}

The authors disclosed no conflicts of interest related to this article.

\section{REFERENCES}

1. Miranda, C.; Pérez-Rodríguez, Z.; Hernández-Armengol, R.; Quiñones-García, Y.; Betancourt-Purón, T.; Cabrera -Pérez, M. Á. Biowaiver or bioequivalence: ambiguity in sildenafil citrate BCS classification. AAPS PharmSciTech. 2018, 19, 1693-1698. DOI: 10.1208/s12249-018-0982-7.

2. Unegbu, C.; Noje, C.; Coulson, J. D.; Segal, J. B.; Romer, L. Pulmonary hypertension therapy and a systematic review of efficacy and safety of PDE-5 inhibitors. Pediatrics. 2017, 139, e20161450. DOI: 10.1542/peds.2016-1450.

3. Bunaciu, A. A.; El Nashar, R. M.; Aboul-Enein, H. Y. Mini review: determination of sildenafil citrate in pharmaceutical preparations. Anal Lett. 2011, 44, 2085-2093. DOI: 10.1080/00032719.2010.546019.

4. Zayed, R.; Kamel, A. O.; Shukr, M.; El-Shamy, A-H. An in vitro and in vivo comparative study of directly compressed solid dispersions and freeze dried sildenafil citrate sublingual tablets for management of pulmonary arterial hypertension. Acta Pharm. 2012, 62, 411-432. DOI: 10.2478/v10007-012-0027-9.

5. WHO Expert Committee on Specifications for Pharmaceutical Preparations. Multisource (generic) pharmaceutical products: guidelines on registration requirements to establish interchangeability; WHO Technical Report Series, No. 1003, Annex 6; World Health Organization, 2017; pp 181-236.

6. Viagra is already sold in 34 more varieties than aspirin. [in Spanish] Argentine Pharmaceutical Confederation website. April 3, 2013. http://www.cofa.org.ar/?p=2905 (accessed October 30, 2020).

7. Perez López, E. Comparative analysis of content uniformity sildenafil tablets ( $50 \mathrm{mg} / \mathrm{tab}$ ), an original and generic medicinal product. Revista Pensamiento Actual. 2014, 14, 71-80.

8. Ali Audu, S.; Ogunbameru, W.; Sani, M. A.; Ojuolape Abdulraheem, R.; Abdulraheem, R. B. Quantitative determination of sildenafil citrate in commercial tablet dosage form marketed in Mauduguri Metropolitan Council (MMC). Int. Res. J. Pharm. 2012, 3, 91-93.

9. Deconinck, E.; Andriessens, S.; Bothy, J. L.; Courselle, P.; De Beer, J. O. Comparative dissolution study on counterfeit medicines of PDE-5 inhibitors. J. Pharm. Anal. 2014, 4, 250-257. DOI: 10.1016/j.jpha.2014.03.002.

10. Argentine Pharmacopeia, 7th ed. Administración Nacional de Medicamentos, Alimentos y Tecnología Médica (ANMAT): Buenos Aires, 2013.

11. ANMAT 5904 Regulation: Definitions and general guidelines on how the information should be included in the leaflets of pharmaceutical products whose condition of sale is under prescription; Administración Nacional de Medicamentos, Alimentos y Tecnología Médica: Buenos Aires, 1996. http://www.anmat.gov.ar/webanmat/NORMATIVA/NORMATIVA/MEDICAMENTOS/DISPOSICION_ANMAT _5904-1996.PDF (accessed October 30, 2020).

12. Sivakranth, M.; Althaf, A. S.; Rajasekhar, S. Formulation and evaluation of oral fast dissolving tablets of sildenafil citrate. Int. J. Pharm. Pharm. Sci. 2011, 3, 112-121.

13. The United States Pharmacopeia and National Formulary USP 41-NF 36. The United States Pharmacopeial Convention, Inc.: Rockville, MD, 2018.

14. Khan, K. A. The concept of dissolution efficiency. J. Pharm. Pharmacol. 1975, 27, 48-49. DOI: 10.1111/j.2042-7158.1975.tb09378.x.

15. Costa, P.; Sousa Lobo, J. M. Modeling and comparison of dissolution profiles. Eur. J. Pharm. Sci. 2001, 13, 123-133. DOI: 10.1016/S0928-0987(01)00095-1. 